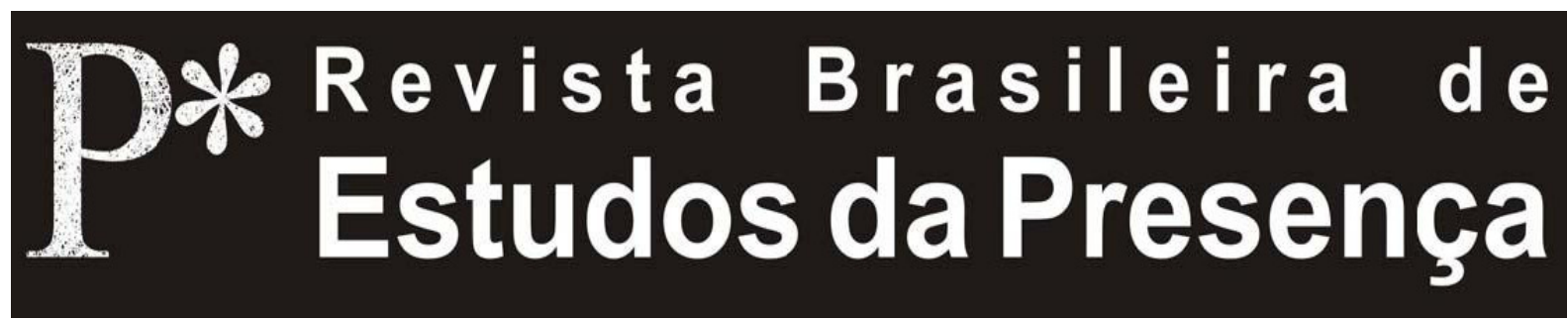

DOI - http://dx.doi.org/10.1590/2237-266020985

ISSN 2237-2660

\title{
A Vanguarda Conservadora
}

\author{
Richard Schechner \\ New York University - NYU, Nova York, Estados Unidos da América
}

RESUMO - A Vanguarda Conservadora - Este artigo trata da suposta condição vanguardista das artes no século XXI, em especial no que concerne às artes cênicas e performativas; dito de outro modo, o texto pergunta pela situação atual dessas formas de expressão. Discute, assim, os conceitos de vanguarda, de nichoguarda e de conservadorismo, a fim de discorrer sobre o estatuto conservador das vanguardas no conjunto de expressões artísticas anteriormente mencionadas, as quais antes repetem feitos passados do que propriamente propõem novas formas de transgressão e interrupção da ordem vigente, incluindo-se aí aquela que rege o próprio sistema das artes. Parte-se do pressuposto que a vanguarda existe simultaneamente em três domínios - como tradição viva, como marca e como o eco ou fantasma da provocação que ela foi um dia.

Palavras-chave: Arte. Vanguarda. Performance. Estudos da Performance. Produção Cultural.

ABSTRACT - The Conservative Avant-Garde - This article discusses the so-called artistic avant-garde in the twenty-first century, particularly in regard to theatre and performance art; in other words, this text brings into question the current state of those forms of expression. It discusses the concepts of avant-garde, nicheguard and conservatism in order to deal with the conservative status of the avant-garde in the group of artistic expressions mentioned above, that actually merely repeats previous achievements rather than proposing new forms of transgression and disruption of the established order, including the one that running the art system. The article is based on the idea that the avant-garde exists in three realms simultaneously - as a living tradition, as a brand, and as the echo or ghost of the provocation it once was.

Keywords: Art. Avant-Garde. Performance. Performance Studies. Cultural Production.

RÉSUMÉ - L'Avant-garde Conservatrice - Cet article aborde la question de la supposée condition avant-gardiste des arts au XXI ${ }^{\text {ème }}$ siècle, notamment en ce qui concerne les arts du spectacle et les arts performatifs; autrement dit, il s'interroge sur la situation actuelle de ces formes d'expression. Le texte propose donc une réflexion autour des concepts d'avant-garde, de niche-garde et de conservatisme, afin de montrer le statut conservateur des avant-gardes dans l'ensemble des expressions artistiques mentionnées auparavant, lesquelles répètent davantage de faits passés qu'elles ne proposent effectivement des formes de transgression et d'interruption de l'ordre courant, y compris celui qui régit le système même des arts. Cette réflexion s'appuie sur le présupposé que l'avant-garde existe simultanément sous trois formes - en tant que tradition vive, comme une marque et, enfin, comme l'écho ou le fantasme de la provocation qu'elle a été un jour.

Mots-clés: Art. Avant-garde. Performance. Etudes de la Performance. Production Culturelle. 
A atual situação do teatro e da performance norte-americanas é a de uma imobilidade cíclica, um sistema neomedieval que faz negócios em nome da globalização. Trata-se mais de uma Nichoguarda do que de uma vanguarda, por um longo tempo essa arte tem se estabelecido em seus vários locais geográficos e conceituais. Ela não está à frente de nada. Sim, há muitos trabalhos novos, se por novo entendermos apresentações muito bem realizadas - muitas de repertórios criados há anos ou mesmo décadas atrás - por artistas já estabelecidos ou por artistas novos, como também por trabalhos de grupos não tão conhecidos, tais como o TEAM, o Nature Theater of Oklahoma ${ }^{1}$, Witness Relocation, Pig Iron, Big Art Group, National Theater of the USA ${ }^{2}$, e muitos outros ${ }^{3}$. Nichoguar$d a$, pois os grupos, artistas e trabalhos promovem, ocupam e funcionam como marcas muito bem conhecidas. Os grupos mais novos seguem o exemplo exato de seus predecessores no padrão familiar tanto da tradição quanto de marketing: ganhe muito, mude pouco e faça com que algo antigo pareça novo de forma empolgante. Tal como acontece com a política da identidade, o politicamente correto e a ortodoxia acadêmica (um novo cânone que vai de Foucault a Derrida, de Fredric Jameson a Richard Schechner), a vanguarda é conhecida antes de ser vivida (de novo). Muitos desses trabalhos - de grande valor conceitual, performativo e técnico - são profundamente conservadores esteticamente.

Mas o que é conservador? Há pelo menos dois tipos de conservadorismo. Eu não me refiro ao Tea Party, mas a algo em sintonia com reduzir, reutilizar, e reciclar, ser sustentável, e deixar rastros menores - como respeito por e conservação dos ecossistemas do planeta e a sua miríade de culturas locais, tanto humanas quanto animais. Esse tipo de conservadorismo não é intervencionista - exceto pelas intervenções em nome dos ameaçados. O conservadorismo do Tea Party é muito diferente, podendo ser traçado nos Estados Unidos (EUA) desde o partido anterior à Guerra Civil, anti-imigração e anticatólico Know Nothing, oficialmente o American Party, cuja filiação era reservada exclusivamente a homens brancos protestantes. 
O conservadorismo do Tea Part Know-Nothing é, na verdade, radical, quase anarquista, o qual sintoniza com a oposição à autoridade típica dos manifestos das vanguardas do século XX. Naturalmente, os programas de ambos os tipos de conservadorismo não podem ser reduzidos ao binômio de radicais versus conservadores: o que acontece no palco mundial e nas artes é muito mais complicado do que isso. Todavia, é verdade que as vanguardas históricas, tanto em suas encarnações artísticas quanto políticas - digamos, do futurismo e dadaísmo ao surrealismo e situacionistas; de Alfred Jarry a Antonin Artaud e ao Living Theatre; de Trotsky a Mao, de Che Guevara a Franz Fanon - defendiam fortemente a interferência, derrubada e anarquia - a catarse revolucionária como prelúdio para uma nova ordem mundial. Esse tipo de vanguarda, como já argumentei em outras ocasiões, foi implementada de forma literal pelos que realizam espetáculos de terror, tais como o ataque ao World Trade Center em Nova York em 11 de setembro de $2001^{4}$. A nova ordem mundial, por sua vez, está surgindo na forma de uma corporação global. Por corporação quero referir um sistema que interliga empresas, governos, ideologias e religiões. Não há nada fora da corporação. Paradoxalmente, em meio a flutuações e desequilíbrios econômicos - muitos dos quais são organizados de forma a se obter maiores lucros - e em harmonia com guerras intermináveis, mas limitadas, com terrorismo e religiosidade virulenta, o que está surgindo é uma estabilidade oculta, semelhante à da Europa medieval, uma estase baseada na interdependência das partes do sistema. Adversários aparentes são, na realidade (mesmo que sem o saber), aliados, da mesma forma como criminosos, policiais e juízes são codependentes. O consenso do que compreende o conhecimento básico são as áreas $\mathrm{STEM}^{5}$. Todos, desde os fundamentalistas e jihadistas aos cibercriminosos chamados de Anonymous, aderem ao uso da infraestrutura da informação corporativa $^{6}$ - a internet, o armazenamento e transmissão de dados digitais, a captação de imagens por satélite e redes globais subvertem e transcendem as nações. Pessoas que moram afastadas umas das outras geograficamente estão próximas em termos de telecomunicações. A afinidade (ou poder-se-ia dizer camaradagem?) daqueles que pensam/acreditam nas mesmas 
coisas e não daqueles que estão próximos é o que faz com que os nichos existam. O espaço da rede toma o lugar do espaço geográfico. Grandes Manifestações - os comícios dos rivais Glenn Beck e Stephen Colbert em Washington em agosto e outubro de 2010 são bons exemplos - misturam entretenimento e política ${ }^{7}$. Não sou um grande entusiasta dessa nova ordem mundial. Mas, tampouco sou contra ela irrefletidamente.

II

Para trazer essa discussão de volta às artes: a nichoguarda de hoje promulga alterações das circunstâncias sociais, culturais e políticas muito diferentes das vanguardas históricas. A cada ano, a historicidade, e não a atualidade da vanguarda, é vista com mais clareza. As vanguardas tiveram seus inícios, seus momentos de prosperidade e seu fim (para ser Aristotélico sobre o assunto). As vanguardas começaram no século XIX como um fenômeno Europeu fortemente ligado à expansão colonial e à industrialização. Elas não teriam sido sequer imaginadas sem as filosofias dos séculos XVII e XVIII do Iluminismo - principalmente Immanuel Kant -, que consideravam que a arte podia ser pensada em seus próprios termos, enquadrada e isolada de outros tipos de processos ou coisas; a arte pela arte, pode-se dizer. Mas, também, a arte pelo mercado. Aquilo que pode ser enquadrado e isolado pode igualmente ser facilmente avaliado e vendido. Em nossos dias, não são apenas as coisas, os objetos de arte, que são enquadrados e isolados, mas também comportamentos. Esse enquadramento do comportamento como a contrapartida performativa a pinturas e obras desse tipo é o que está por trás da obsessão atual por reperformances, como a repetição de 18 Happenings in 6 parts, de Allan Kaprow ou a retrospectiva de Marina Abramovic no Museum of Modern Art em 2010, The Artist is Present. Naquela apresentação, performances antigas de outros artistas foram refeitas acompanhadas de um novo trabalho - no qual Abramovic permaneceu sentada por uma semana em uma cadeira, no centro do grande hall de entrada do MoMA, enquanto as pessoas aguardavam durante horas para ter a chance de sentar-se diante dela, com os olhos fixos 
em uma criatura a meio caminho entre a Rainha Elizabeth e Nossa Senhora de Lourdes ${ }^{8}$. Os remakes de Kaprow e Abramovic - e muitos outros remakes recentes - são fundamentalmente diferentes, por assim dizer, do reencenamento do ciclo do Anel dos Nibelungos de Wagner no Met, nos quais o que é solicitado é uma nova visão sobre um texto ou partitura antiga. $\mathrm{O}$ que se pede de Kaprow, Abramovic, entre outros, são eventos os mais próximos o possível dos originais, como se performances fossem pinturas, tal qual a Mona Lisa ou Demoiselles d'Avignon; ou seja, não se tratam de reconstituições instantaneamente perecíveis, mas coisas disponíveis para serem experimentadas em sua pureza - novamente.

Essa repetição toda depende da formação de uma marca e de marketing. Uma marca é um produto tornado familiar, imediatamente reconhecível, tornado necessário por meio de publicidade e outros tipos de marketing. A formação de marca depende em grande parte da repetição de slogans e da reprodução de imagens, de forma muito repetitiva. Esse tipo de reprodução é o contrário da afirmação da vanguarda de que ela é nova ou a primeira ou única. No entanto, as coisas são como são, essa afirmação tornou-se ela mesma uma marca, uma vez que a vanguarda era por definição imprevisível, e mesmo repulsiva - alguns trabalhos eram de fato chocantes. Mas a vanguarda de hoje habita o já conhecido, vendida como algo que se encaixa em categorias ou marcas. Espectadores, eruditos, patrocinadores e produtores de festivais sabem o que esperar quando telefonam para o Wooster Group, Lee Breuer, Richard Foreman, Laurie Anderson, Robert Wilson, Anne Bogart, Builders Association, Elevator Repair Service, ou quem quer ou o que quer que seja. Da mesma forma que as políticas de identidade, que o politicamente correto e a ortodoxia acadêmica, todos sabem o que é a vanguarda antes mesmo de ser experimentada.

Mas, nessa linha positiva, muitos trabalhos de vanguarda estão em um nível conceitual e técnico muito elevado. Nas minhas décadas de experiência, a qualidade das vanguardas na performance nunca foi tão alta. Alguns grupos e artistas proporcionam extremo formalismo; outros levam o realismonaturalismo aos seus limites cotidianos; alguns expõem his- 
tórias políticas e sociais bastante complexas; alguns celebram estilos de vida e orientações sexuais alternativas; alguns promovem a criatividade coletiva e trabalhos concebidos em grupo; outros promulgam visões autorais únicas. Essa diversidade e qualidade é tão verdadeira nos grupos e artistas novos quanto nos já estabelecidos. Os novos artistas surgem já bem treinados, pensantes e totalmente equipados para realizar trabalhos soberbos que merecem a nossa atenção e aplausos. Por exemplo, entre os novíssimos grupos de vanguarda em Nova York estão o Nature Theater of Oklahoma, o National Theater of the United States of America, o TEAM, o Radiohole, o New York City Players, o Big Dance Theater e o Pig Iron, como também outros que surgem a todo o momento. Os mais estabelecidos são a companhia SITI de Anne Bogart, a Elevator Repair Service, e a Builders Association. Esses grupos frequentemente estreiam seus novos trabalhos longe de Nova York, mesmo que essas companhias tenham suas sedes nessa cidade. Ironicamente, dado o exagero de que nada poderia estar mais longe da Broadway do que a vanguarda, as turnês e as comissões fora do país funcionam exatamente como os out of town tryouts da Broadway - semanas na estrada antes da estreia no Great White Way. Estreias fora da cidade oferecem aos grupos de vanguarda a oportunidade não apenas de polir o seu trabalho como também de coletar reconhecimento crítico, o qual é usado para promover as novas produções junto a espectadores dispostos a pagar caro por ingressos. Por exemplo, Gatz, do Elevator Repair Service - uma leitura dramática com seis horas de duração de The Great Gatsby, de F. Scott Fitzgerald - chegou "finalmente" a Nova York em 2010, como destaca o website do ERS, "cinco anos após sua criação e dez anos após sua concepção"

Um grupo ainda mais antigo de vanguardistas está ainda produzindo trabalhos de ampla aceitação: o Wooster Group, Robert Wilson, o Ontological-Hysteric Theatre de Richard Foreman, Mabou Mines e o Living Theatre (fundado em 1947 como uma alternativa criativa ao teatro comercial $)^{10}$. A vanguarda já foi considerada um domínio dos jovens, mas a comunidade de vanguarda de hoje inclui muitos artistas com mais de setenta anos de idade e mostra poucos sinais de 
abrandamento. Não é apenas o fato de que artistas mais velhos produzam ainda trabalhos experimentais - isso é frequentemente uma realidade -, mas o fato de que esses artistas e seus trabalhos são acolhidos por artistas mais novos. Certamente nos EUA, provavelmente na Europa e possivelmente em todos os lugares, o que é rotulado de avant-garde não está avant ou à frente de nada. Muito pelo contrário, uma tradição da vanguarda surgiu, criou raízes e guia o contínuo processo de desenvolvimento. Essa tradição está repleta de linhagens, estilos, temas e modos de produção facilmente identificáveis. Uma linhagem relacionada poderia ser traçada a partir da dança de vanguarda de Anna Halprin e dos dançarinos da Judson Church; ou até mesmo anteriormente, de Ruth St. Denis até Martha Graham passando por Merce Cunningham e além; ou às performances de John Cage e Allan Kaprow. Esses fundadores - em todas as artes do espetáculo - estão, por sua vez, conectados às vanguardas históricas, ao futurismo, ao surrealismo e dadaísmo. O que quero dizer é que a tão propalada vanguarda envelheceu, e certamente se aprimorou, nos seus usos da tecnologia, mídia, internet e na qualidade da performance, entretanto, ela não é mais, e já não tem sido por muitos anos, vanguarda no sentido comum do termo. As palavras vanguarda e experimental são úteis como formação de marca, mas elas não são descritivas. Até mesmo a palavra alternativo levanta a questão: alternativo a quê?

Inovação e excelência estão em uma relação inversa uma com a outra. Quando a inovação é alta, a excelência é baixa; e vice-versa. Isso não é sempre verdadeiro, mas opera como uma tendência geral. Isso faz sentido, visto que quando as pessoas experimentam a maior parte do que elas tentam não dá certo. Na ciência e na engenharia os fracassos raramente chegam ao mercado; nas artes, contudo - e especialmente na performance, porque ela é uma arte que precisa de uma audiência e uma arte cujos trabalhos não podem ser trancafiados à espera de tempos mais receptivos da mesma forma que romances e pinturas - performances fracassadas são realizadas na presença do público. Seja como for, ao longo do tempo, enquanto os processos experimentais são aperfeiçoados e novas formas, novos espaços e novos estilos de atuação/ 
performance são tentados, testados, aprimorados e aceitos, o sucesso substitui o fracasso. Hoje nós nos encontramos em um período de grande excelência e pouca inovação. De uma maneira geral, as vanguardas não mudaram muito em quase cem anos. Ou melhor, elas não mudaram mais do que, digamos, o realismo mudou em um período de tempo semelhante. A gangorra da inovação/excelência explica por que hoje em dia performances estimulantes e instigantes abundam, ainda que o conhecedor das vanguardas sinta que não há nada de novo. Para as audiências mais comuns, que apreciam as vanguardas em grandes teatros já estabelecidos, há o efeito Miranda de A Tempestade: grupos e práticas vão de lugares alternativos para os do mainstream, aparecendo ao público em geral (e seus críticos da imprensa mainstream) como um admirável mundo novo ("Para ti isso é novo").

Se houvessem mais performances ruins ou inaceitáveis, isso assinalaria o aparecimento de verdadeiras vanguardas, um verdadeiro antes de. Ao invés disso, o que vemos são os chamados novos trabalhos coexistindo em harmonia com reprises, como a produção de Satyagraha (1980), de Philip Glass, em 2010, a célebre performance de Abramovic no MoMA em 2010, a reinvenção, em 2004, de Jerzy Grotowski e William Forsythe em Poor Theater: A Series of Simulacra e o Hamlet de 2007, em que é utilizado o registro de uma transmissão ao vivo de Richard Burton, em 1964 ${ }^{11}$. Cada uso genial da mídia ou multimídia, cada uso não-ortodoxo do espaço ou trabalhos feitos para locais específicos, cada tentativa de incluir o público, cada inclusão das vidas reais dos performers na ficção, cada coisa - qualquer coisa - já foi feita antes, porém, talvez não tão bem.

Junto a essas reutilizações de ideias antigas há um forte retorno ao texto. Rejeições da literatura, do texto, autores e autoridade foram o marco das vanguardas históricas e até mesmo da grande explosão de atividade, a partir do final da década de 1950 até a década de 1980. A sua retórica incluía queimar bibliotecas e pilhar museus. No teatro, eu não era o único a defender a rejeição das palavras tal e qual escritas por dramaturgos, começando, ao invés disso, com as pessoas presentes na sala; desconstruindo textos; distorcendo-os; fazendo 
colagens com eles; e assim por diante. O Wooster Group, em uma série de trabalhos conhecidos de meados da década de 1970 até os anos 199012, em Nayatt School, Route 1 \& 9, LSD: Just the High Points, Fish Story, e To You, the Birdie! montou peças de T. S. Eliot, Thornton Wilder, Arthur Miller, Anton Tchekhov e Jean Racine. Contudo, na virada do século uma grande mudança ocorreu - o texto-como-texto reafirmou-se. Mesmo que um trecho de $L S D$ desconstruísse The Crucible, de Miller, a peça abria com os performers do Wooster com livros na mão e lendo algumas de suas partes favoritas sobre drogas que alteram a percepção. O Elevator Repair Service, influenciado pelo Wooster, levou a ideia de texto-como-texto adiante ao encenar parte de $O$ Som e a Fúria, de William Faulkner, e depois ao ler cada palavra de The Great Gatsby, de F. Scott Fitzgerald. Essas performances não eram teatro no sentido ortodoxo do termo, e tampouco leituras dramáticas, como as novas peças-em-desenvolvimento realizam para atrair produtores. As leituras colocam o texto - tanto como palavras ouvidas quanto objetos físicos, o livro - no centro da performance. Os performers proferiam cada "ela disse" e "ele disse", cada expressão descritiva. O livro como objeto estava sempre presente. A leitura foi feita em combinação com a atuação teatral. Os personagens dos romances irrompiam tanto como seres vivos (teatro) e objetos literários (leitura). Essa prática - que penso se tornar cada vez mais frequente é totalmente condizente com enviar mensagens de texto em telefones celulares, constituindo uma fusão de categorias de discurso visual e objetos audíveis ${ }^{13}$.

\section{III}

A vanguarda anuncia a si própria usando a retórica do novo enquanto pratica o já estabelecido. Como se observa, isso está em consonância com ideias de conservação e reciclagem, em vez da defesa vanguardista de se destruir tudo e começar do zero. Nas artes, a tendência a conservar e reciclar é enormemente suportada pela fácil disponibilidade do que equivale a um arquivo infinito preservado digitalmente. Nessas circunstâncias, como David Savran, escreve, longe de 
estar em frente ao resto da sociedade, a vanguarda desenvolve "logotipos e identidades de marcas distintas" de acordo "[...] com as grandes mudanças no mercado [do mesmo modo que a] Calvin Klein, Nike, Starbucks, Martha Stewart, e a Body Shop (entre muitos outros)" o fazem. Savran passa a notar que

[...] ironicamente, a produção da vanguarda como uma marca, alucinação coletiva e produtos infinitamente sedutores e prestigiosos, não são tanto sinais de uma modificação, mas de uma inversão completa de seu significado original (Savran, 2005, p. 36).

Assim, paradoxalmente, a vanguarda existe simultaneamente em três domínios - como tradição viva, como marca e como o eco ou fantasma da provocação que ela foi um dia.

A vanguarda é conservadora quando se alia à cultura popular, pois a cultura pop não é apenas impulsionada pela publicidade, também se funde com ela. De Marcel Duchamp a Andy Warhol e Roy Lichtenstein até os dias de hoje, a vanguarda difere do pop não por causa de ações ou imagens específicas, mas por causa do estado de ânimo que um espectador ou ouvinte traz a uma atividade. Um urinol e o objeto de arte chamado de Fonte não são distinguíveis um do outro exceto pela atitude do público (e da opinião do conhecedor de arte). A diferença entre a imagem de um rótulo de sopa Campbell's real, na lata, e a versão de Warhol de uma lata de sopa Campbell's ou um painel com muitas delas (como se estivessem na prateleira de um supermercado, mas sem a prateleira) é a diferença de atitude e contexto. Esse foi um dos pontos-chave de Warhol: atitude e contexto são tudo. Da mesma forma, há muito tempo na dança, aquilo o que separava a vida cotidiana da vanguarda foi destruído pelo uso de movimentos e falas do dia a dia pelos dançarinos da Judson. $\mathrm{O}$ mesmo vale para a normalidade ritualizada dos happenings de Kaprow. Nessa conjuntura, graças às teorias esotéricas e influentes de John Cage - baseadas na sua devoção tanto à centralidade presente do Zen Budismo e ao acaso/indeterminação como constituindo o processo fundamental da criação (musical) - o próprio ato de observação desinteressada (do quê? qualquer coisa/tudo) cria arte. Tudo isso aponta para a 
dissolução da vanguarda como uma categoria formal distinta. Até mesmo as operações mais comerciais - da Broadway e de Hollywood aos videogames e websites interativos - utilizam ideias e técnicas que ainda são a matéria-prima essencial da vanguarda. O fluxo requintadamente fácil, digamos, de $O R e i$ Leão, de Hollywood, e a titeragem de vanguarda (há tempos atrás) de Julie Taymor, na Broadway, é uma evidência dessa fusão.

A vanguarda está em circulação - mas essa circulação é estática. Os mesmos itens, ideias, técnicas e tipos de espetáculo vão e voltam sendo assistidos pelos mesmos tipos de audiência. Como já mencionado, o trabalho é muitas vezes de altíssima qualidade. O circuito de festivais segue mercados mundiais, com o domínio da América do Norte-Europa e Ásia-Austrália. Mercados menores conectam as Américas. Em 2007, o décimo nono Experimental Theater Festival aconteceu no Cairo com apresentações de peças indo desde 4.48 Psychosis de Sarah Kane até King Lear as a Sufi. Quando os artistas são bem sucedidos em mercados menores, eles são recrutados pelos maiores - Rabih Mroué do Líbano é, por exemplo, presença frequente na Europa. A África Subsaariana, tanto diretamente quanto através da influência Afro-Americana, oferece música, linguagens, estilos e artistas sem ainda participar de turnês (exceto ocasionalmente na África do Sul). Apesar desta desigualdade de circulação, a vanguarda é cada vez mais intercultural em pessoal, temas e técnicas. As audiências são minúsculas em comparação as da música pop, do cinema, do vídeo/DVD e da internet. Pessoas que assistem a espetáculos de vanguarda sabem o que esperar e geralmente apoiam o trabalho que assistem. O épater le bourgeois da vanguarda histórica não mais se dirige ao espectador mas, se minimamente eficiente, é direcionada aos governos, corporações, e outros agentes do lado negro. Os ataques são muitas vezes de má-fé, pois os atacantes apelam para esses mesmos governos, pessoas ricas, empresas e fundações que eles atacam. Vanguardistas - tais como comediantes stand-up (e alguns o são) - procuram a aceitação e dinheiro daqueles que eles ridicularizam. Festivais são muitas vezes financiados pelo público, não por respeito à arte, mas porque a arte é uma atração turística. Em relação a 
este mundo mais amplo do qual faz parte, mesmo enquanto finge estar fora dele, a vanguarda produz um ruído irritante, de estática, aos ouvidos da macroeconomia.

\section{IV}

Vamos nos aprofundar um pouco mais sobre as circunstâncias que transformaram a vanguarda de radical em conservadora. O ano de 1968 foi um divisor de águas, com confrontos entre jovens rebeldes e as autoridades na Cidade do México, Paris e Chicago. Os conservadores derrotaram os estudantes nas ruas, mas não (naquela época) as suas mentes e imaginação. Nos EUA, os assassinatos de Martin Luther King Jr. e Robert F. Kennedy puseram fim ao otimismo em relação a mudanças reais causadas pelas ou impostas às classes dominantes. Muitos intelectuais e artistas se refugiaram na academia, onde eles criaram uma poderosa vanguarda $d a$ teoria, mesmo que eles evitassem ações radicais nas ruas. Essa retirada se acelerou e se aprofundou ao longo dos anos setenta e oitenta. Essas duas décadas foram formativas para os estudos da performance, o que eu apelidei de abordagem de amplo espectro para performances em todas as áreas e aspectos da vida e do pensamento.

Paralelo a isso, o período que foi do final da década de 1970 até o início dos anos de 1990 viu o fim de uma oposição significativa ao capitalismo: na China, as reformas de Deng Xiaoping (socialismo com características chinesas), na Europa, a queda do muro de Berlim em 1989 e o colapso da URSS, em 1991. Entrementes, ocorreram as manifestações de maio-junho de 1989 de milhares de estudantes chineses que ocuparam a Praça da Paz Celestial, em Pequim. Esses impetuosos defensores da democracia e transparência foram mortos a tiros pelo Exército de Libertação Popular. O Marxismo como sistema econômico e ideia libertadora estava morto, mesmo que os comunistas detivessem ainda o poder na China, Coreia do Norte e em Cuba.

Entre os radicais com empregos estáveis que assistiram, escreveram sobre e tiveram suas memórias perturbadas por esses eventos, o pós-estruturalismo e os estudos da performan- 
ce foram continuações, em termos de teoria, das revoluções econômicas e políticas fracassadas encabeçadas por estudantes e artistas de esquerda. À medida que o mundo aceitava ou era forçado em direção a uma economia de mercado capitalista, os Marxistas/desconstrucionistas acadêmicos imaginaram um mundo moldado por atos de fala e performativos, com hierarquias invertidas, binômios invertidos e sem narrativas mestras. Neste mundo, mudanças verdadeiras em benefício das pessoas comuns não eram mais promulgadas (como poderiam ser, dada a intensificação da globalização?); em vez disso, as mudanças foram consideradas como acadêmicas. As mudanças foram imaginadas e teorizadas dentro das grandes empresas; como tal, essas mudanças nunca poderiam tornar-se realidade. O que não era - não poderia ser - realizado através de ação política direta era pensado e teorizado por catedráticos e estudantes. Acadêmicos radicais, tanto professores quanto estudantes, fizeram ou estudaram a arte da performance, participaram de ações em ambientes virtuais, como também trocaram ideias em conferências (a versão acadêmica das turnês).

Atualmente, nos EUA, universidades com espírito corporativo estão trocando os vínculos estáveis por algo mais quantificável em termos de produtividade - o crescimento do número de professores adjuntos, contratos temporários e trabalhadores a tempo parcial. A universidade, não mais uma torre de marfim, está cada vez mais fazendo parte do mundo corporativo, ao invés de estar do lado de fora. Nesse ambiente acadêmico instável, a maioria dos estudantes e seus pais já compreenderam a mensagem e voltaram-se aos negócios, às ciências, ao direito ou à engenharia (STEM, novamente). A maior parte dos estudantes no campo das artes busca formação prática, na esperança de conseguir uma carreira no teatro comercial, mídia ou cinema. Alguns realmente estudam performance de vanguarda, como na Tisch School of the Arts Experimental Theater Wing (TSOA), da New York University. Também na TSOA há o Departamento de Estudos da Performance, o parceiro acadêmico de vanguarda. Muitos alunos de estudos da performance são performers. Alguns também são ativos em teatro social, ou performance ativista, como as de Boal, em escolas, prisões, abrigos para os sem teto e locais semelhantes. 
Entretanto, há muito pouca agitação nas ruas. Até mesmo a palavra trabalhadores nos soa estranha e fora de moda em um mundo onde todos parecem querer ascender à classe média ou alta. Em uma economia de recesso, terceirizada, os trabalhadores não são mais uma categoria organizável. O trabalho é outro exemplo de circulação da estase. Estabeleceu-se um medievalismo pós-moderno.

Esse medievalismo é mais conceitual do que econômico ou político. Ele se revela como a nichoguarda à qual eu me referi anteriormente: a redução de ideias, antes grandiosas, em pacotes menores de entidades interligadas subsumidas pela corporação. A corporação é um sistema tão opaco que os seus agentes não o compreendem e nem são capazes de fazê-lo. Nós estamos incluídos nela e governados por ela, sem sermos capazes de compreendê-la. Vista por esse ângulo, a vanguarda - como marca, mas também como entidade legítima -durou cerca de cem anos, mais ou menos desde Et Dukkehjem (Casa de Bonecas) de Henrik Ibsen, em 1879, até LSD do Wooster Group, 1983-85 (essas datas vão desde os primeiros ensaios gerais até a estreia do trabalho final). Artistas de vanguarda orgulhavam-se de sua originalidade, inovação e a rejeição, e mesmo pela total destruição do passado. As vanguardas eram preenchidas com ideias e ações que orbitavam ao redor de palavras (em Inglês, com seus homólogos em outros idiomas) como novo, vivo, anti-, agressivo, violento, e assim por diante, com a intenção clara (retórica, talvez verdadeira) de destruir tanto as ordens sociopolíticas quanto estéticas. De fato, no campo da estética, o novo marchava atrás do novo, do futurismo, do cubismo, assim como do construtivismo para o surrealismo e dadaísmo ao expressionismo abstrato, a arte conceitual, o teatro ambiental, a pop art, e a abolição das hierarquias, de modo que Allan Kaprow podia falar com confiança sobre arte como arte e arte como vida, preferindo essa última ${ }^{14}$.

A tensão dinâmica que Kaprow apreciava e explorava deu energia para uma explosão de novas atividades performáticas nos anos sessenta e setenta, a última dessas estrelas novas. Os happenings - que mais tarde foram chamados de performance artística -, assim como vários tipos de teatro experimental, aconteciam em vitrines, nas ruas, em prisões 
e outras instituições totais, em galerias de arte, em qualquer lugar. Essa atividade levantou questões profundas: o que é performance? Onde ela acontece? Qualquer pessoa pode fazer uma performance? Um evento performático - não mais uma peça ou concerto, ou teatro, dança, ou música como tais, mas um evento - deve acontecer de uma maneira linear e, se não, o que lhe confere unidade? Ele precisa de unidade? O que é unidade? Qual é a relação entre as artes performáticas, a cultura popular, a política, rituais, terapia, esportes e jogo? E o que dizer das formas de performance que não são arte? Performances na vida cotidiana, negócios, medicina e assim por diante? Na segunda década do século XXI, essas perguntas parecem resolvidas, ou absurdas. É claro que a performance acontece em qualquer lugar e pode incluir qualquer coisa. $\mathrm{E}$ se não, e daí? O que vai acontecer agora? não constitui mais uma pergunta relevante - pois qualquer coisa pode acontecer, irá acontecer e pode ser absorvida. Isso porque as vanguardas são, como observa Savran,

[...] inelutavelmente ligadas à hierarquia cultural modernista que opõe a arte e o comércio, o esotérico e o popular, o presencial e o mediado, o progressista e o reacionário, o vanguardista e o kitsch. Mas essa hierarquia não mais obtém ou pelo menos não toma a forma que $\mathrm{o}$ tomou durante a maior parte do século XX (2005, p. 35).

$\mathbf{V}$

A vanguarda conservadora causando suas próprias repetições, como o espetáculo de Abramovic no MoMA, a reencenação do Happening de Kaprow, a remontagem de Dionysus in 69 do The Performance Group ${ }^{15}$, e as reperformances de muitos outros trabalhos podem em parte ser explicadas nos termos das teorias da performance desenvolvidas a partir da década de 1970 até os anos de 1980 - e como elas afetaram os artistas de hoje. Na escola, jovens artistas aprendem teorias pós-modernas e pós-estruturalistas. Anteriormente, as diferenças de classe e lutas - o marxismo - eram apresentadas como aquilo que determinava a estrutura social. Um sentido de coletivos globais era pelo menos imaginável. As mais recentes teorias pós privilegiam indivíduos e pequenos grupos, assim 
como a política da identidade (raça, etnia, gênero, orientação etc.), os estudos pós-coloniais e a análise crítica - os quais dão embasamento à nichoguarda. Além disso, na época de ouro das vanguardas históricas os artistas eram treinados através de posições de aprendiz e relações de amizade, trabalhando com artistas que eles admiravam, frequentando os mesmos espaços em que os mesmos costumavam se encontrar. Isso não equivale a dizer que a aprendizagem por associação e pelo trabalho de aprendiz parou de existir, mas que a educação universitária se tornou provavelmente mais importante; e que, assim que se formam em universidades, os novos artistas trabalham com antigos colegas de curso. Os modelos de artista faminto, maltrapilho e aguardando ser descoberto não funcionam mais. Tudo o que pode ser descoberto já está disponível no YouTube, Vimeo, Facebook etc. Pode-se acessar, compartilhar, aprender e copiar desde trabalhos de fundo de quintal e de baixo orçamento até blockbusters. Quanto a performances ao vivo, só em Nova York há uma infinidade de lugares, desde os muito caros até lofts e salas de estar. Seja qual for o seu nível de realização e sofisticação, sempre há um local para mostrar sua produção. De novo, essa profusão de oportunidade leva a nichos. As pessoas precisam achar seu lugar ou então elas se perdem.

O papel da teoria levando a uma vanguarda conservadora é demonstrável. Os pós-estruturalistas e pós-modernistas, tão presentes desde os anos 1970 até a virada do século XXI (e longe de estarem ultrapassados hoje), os defensores do comportamento reformado ou sub-rogação colocavam ênfase na repetição, na citação, no diferimento de sentido, na circulação de ideias, como também na impossibilidade de definição, o que nada é senão uma definição, de coisas originais ${ }^{16}$. A afirmação de Derrida de que "il n'y a pas de hors texte" (não há nada fora do texto) assinalou a enorme mudança no armazenamento e compartilhamento (sampleamento, roubo, reutilização) tornada possível pela conjunção das tecnologias digitais e da internet. Fotografias antigas e gravações sonoras requeriam técnicas manuais altamente sofisticadas. Tornar-se um fotógrafo ou técnico em gravação significava não apenas ser capaz de tirar fotos e gravar sons, mas trabalhar com papel e produtos quími- 
cos por longos períodos em uma sala escura ou com circuitos complexos em um estúdio de gravação. Produzir e publicar fotografias e gravações eram atividades caras. Mais difíceis do que fotografia e gravações em estúdios eram filmes com sons de boa qualidade. A miniaturização e digitalização mudaram tudo isso. O gerenciamento de fotografias e sons digitais resultou em um compartilhamento indiscriminado de imagens democratizadas pelo Photoshop (e programas semelhantes), compartilhamento de arquivos, câmeras portáteis e gravadores digitais. Páginas de internet atendem às novas gerações de artistas cujos trabalhos, talentos e habilidades vão de zero ao infinito. Pessoas que anteriormente não eram capazes de fazer coisa alguma em um quarto escuro aprenderam como processar dados audiovisuais. Milhões de pessoas passaram, portanto, a ter acesso a equipamentos anteriormente caros demais. A nova alfabetização digital, assim como o início da alfabetização na Renascença e no Iluminismo, está mudando a maneira como as pessoas pensam.

Ironicamente, essa explosão de acesso à informação - o eterno novo - gerou certo respeito pelo passado; no início, talvez, um passado pessoal (meu trabalho, minha família, meu arquivo), mas cada vez mais um conjunto compartilhado de domínios - um passado digital que realmente começou, digamos, na década de 1970, e que continua a acumular valor com o passar do tempo, tornando possível o acesso a períodos cada vez mais remotos, à medida que os equipamentos são aperfeiçoados. Trabalhos não-digitais mais antigos, antes armazenados em arquivos de difícil acesso, estão cada vez mais sendo disponibilizados de forma digital. A era adentra em uma circulação contínua e em expansão. Essas relações com o passado são tanto libertadoras quanto limitadoras: há tanto que pode ser feito com tais informações; mas também muita informação relembra a qualquer um que se dispõe a estudá-la de que não há nada novo sob o sol - à exceção talvez do nível da tecnologia para acessar e circular coisas antigas e novas. Nada mais está permanentemente fechado ou totalmente aberto.

A teoria se manteve a par da prática nesses domínios. No final dos anos de 1970 eu comecei a pensar sobre as ideias que 
me levaram às muitas diferentes versões da teoria da restauração do comportamento, a qual atingiu sua forma mais ou menos definitiva em 1985, quando a mesma foi publicada em Between Theater and Anthtropology. Apesar de não perceber isso enquanto estava desenvolvendo a restauração e outras teorias relacionadas, agora vejo que elas estavam realmente minando a ideia predominante das vanguardas históricas. Essa forma de teorização conservadora aconteceu ao mesmo tempo em que eu desenvolvia produções que faziam parte da vanguarda. A tese básica de restauração de comportamento é bem conhecida: o comportamento restaurado é um comportamento de vida tratado tal qual um diretor de cinema trata um pedaço de filme. Esses pedaços podem ser reagrupados e reconstruídos; eles são independentes dos sistemas causais (sociais, psicológicos, tecnológicos) que os trouxeram à existência: eles têm vida própria. A verdade ou motivação original do comportamento pode ser perdida, ignorada ou contradita. A restauração do comportamento é um motor que impulsiona todos os tipos de performance; estética, cotidiana, médica, popular, ritualística etc. Performance quer dizer: nunca pela primeira vez. Performance é o comportamento realizado duas vezes.

Essas ideias se deram de forma paralela ao pensamento de teóricas da performance feministas, tais como Judith Butler, Peggy Phelan, Jill Dolan e Sue-Ellen Case, cujos trabalhos foram desenvolvidos do final dos anos oitenta aos anos noventa e após ${ }^{17}$. As feministas frequentemente recorriam às noções de iteração, citação e historiografia de Foucault, Derrida e Lacan. Um pouco mais tarde, Diana Taylor retomou o problema da relação instável entre prática do corpo e o arquivo em The Archive and the Repertoire (2003). Do ponto de vista da teoria queer, José Muñoz explorou temas similares em Disidentifications (2009) e Cruising Utopia (2009). Todos esses estudiosos enfatizam a construção performativa de identidades sociais e experiência diária; a tensão entre a incorporação (embodiment) e as gravações (nos vários significados do termo); algumas pessoas se referem à apatia da performance - não como uma inatividade, mas como uma estranha presença-como-ausência. Tomadas como um todo, essas teorias elaboram, desenvolvem 
e são elucidadas pela restauração de comportamento e subrogação.

Muitos artistas em formação estudaram com esses e outros acadêmicos com ideias semelhantes. O Departamento de Estudos da Performance da New York University (NYU) - que eu ajudei a conceber no final dos anos 1960 e 1970, e que tomou seu nome atual em 1980 - está repleto não apenas de estudiosos mas também de artistas da performance - diretores, autores, monologuistas, atores, designers, profissionais de mídia - mergulhando nas águas da academia. O número de pessoas normais do teatro é pequeno. Além do mais, o grupo de mais de cinquenta estudantes de mestrado e doutorado utiliza a teoria em seus trabalhos artísticos. Performance como pesquisa é uma descrição cada vez mais comum ${ }^{18}$. O que tem acontecido na NYU nos últimos vinte anos é a norma lá e está se tornando a norma em muitas outras universidades e faculdades. Sim, os departamentos de teatro, dança e música ortodoxas permanecem educando pessoas para serem atores, dançarinos, cantores, designers, diretores, coreógrafos, compositores, escritores, técnicos e assim por diante. Esses são locais - nas Américas, na Europa e na Ásia - que estão formando os jovens artistas mais avançados, muitos dos quais conhecem muito bem as teorias que formam suas ideias e práticas. Teorias que tiram ideias da performance e que dialogam com ela: nem sempre com performances dramáticas - o que o teatro costumava ser - mas com a performance artística, performances midiáticas, colagens performáticas e cada vez mais a reencenação de performances de vanguarda.

Muitos dos mais importantes jovens artistas e grupos de hoje, no mundo todo, estão cada vez mais mergulhados na teoria do que seus antecessores, entre eles, o TEAM, Rimini Protokol, Gob Squad, Nature Theater of Oklahoma, Vivarium Studio, Witness Relocation - e muitos, muitos outros, numerosos demais para listar. Seriam esses grupos de vanguarda? Sim, na medida em que a vanguarda é um estilo, uma incorporação e uma investigação da teoria. E também não, porquanto a prática desses grupos não esteja necessariamente à frente de alguma coisa ou anunciando um programa agressivamente destrutivo em relação ao status quo - diferentemente das 
vanguardas históricas. Seriam esses artistas conservadores no sentido ecológico que eu utilizei anteriormente? Sim, novamente.

VI

Qual é a fonte subjacente da estase em circulação que afeta as vanguardas, mas que, no entanto, não se limita a ela? Ao se tomar uma visão ampla da história por meio da reintrodução da noção - frequentemente criticada, porém, útil - de narrativa mestra, proponho que os povos do mundo estão envolvidos em uma guerra tripartida, a qual coloca a economia de livre mercado de Adam Smith contra a economia socialista de Karl Marx contra os fundamentalismos religiosos, - islamismo, cristianismo, judaísmo e hinduísmo. Sim, estes domínios se sobrepõem e um indivíduo pode pertencer a mais de um domínio; e é até mesmo possível, talvez inevitável, que um número considerável de pessoas estejam divididas dentro de si mesmas. Mas, apesar dessas sobreposições e rupturas, as sociedades humanas - e os indivíduos que compõem essas sociedades - estão em meio a uma luta de séculos sobre como imaginar e realizar uma sociedade melhor, seja por meio da mão invisível de Smith, do "a cada um segundo sua capacidade, a cada um de acordo com as suas necessidades" de Marx ou orientação divina (mas sob a égide de qual Deus?). Quando as narrativas são contraditórias entre si, as pessoas precisam escolher que ação tomar, ou abster-se. No entanto, essa escolha não é apenas uma questão de escolha individual. Os líderes - eleitos, impostos, nomeados - fazem escolhas que afetam multidões. Essas escolhas não são nem determinadas e nem resultado de livre arbítrio: não há ainda nenhum meio (e provavelmente nunca haverá) de determinar o que guia esse tipo de tomada de decisões. Eu destaquei o verbo porque os sistemas envolvidos parecem operar por conta própria, mesmo que eles claramente sejam também uma função da intervenção e escolha humana. Novamente a corporação opera por si mesma. A maior parte dos problemas e pontos críticos sem solução hoje dizem respeito ao contínuo de falhas desses sistemas completamente entrelaçados, porém, 
mutuamente contraditórios. A Guerra ao Terror americana tem semelhanças não somente com a Guerra Fria, mas com as Cruzadas - de ambos os lados. Essa guerra de cavaleiros também é uma luta pelo controle dos mercados. Assim, a Guerra ao Terror tem a face de Jano, olhando ao mesmo tempo para trás, em direção à idade média, e para a frente, em direção ao capitalismo avançado. A liderança chinesa criou sua própria versão da economia de livre mercado, ao mesmo tempo em que suprimiu a dissidência e evitou a desintegração da nação (Tibet, Taiwan, o Fallun Gong e outras tensões internas). Todo esse conflito sem resolução mantém as coisas em movimento - não para a frente, mas em círculos.

E é aí onde as vanguardas entram. Em sua maior parte, as vanguardas históricas eram anarquistas ou esquerdistas se autointitulando radicais, progressivas, ou alternativas e ferozmente contra. Os vanguardistas de hoje não são contra. Ao usar Nova York como exemplo, os jovens artistas aguardam na fila para subir na carreira, das performances em lofts para pequenos teatros como o Collapsible Giraffe e de lá para o PS 122 ou o La Mama, até onde muito poucos chegam: ao Lincoln Center Festival ou ao Next Wave Festival da Brooklyn Academy of Music. A partir dos níveis intermediários e acima deles, muitos dos artistas e grupos chegam ao cenário internacional. Eles estreiam seus trabalhos em qualquer lugar onde o dinheiro os levar, onde patrocinadores puderem ser encontrados. Como a Lexus ou a Sony, esse tipo de vanguarda foi testada e comercializada no mercado global, com consequências na imprensa e junto ao público. Nova York na realidade recebe poucas estreias dos grupos mais antigos e mais caros. Até mesmo grupos de nível intermediário como o TEAM procuram por espaços que os patrocinem, fora dos EUA, onde o núcleo criativo pode criar novos trabalhos. Architecting, com temas extremamente americanos, estreou na Escócia. Não se pode falar de radicalismo político no nível de Robert Wilson, o Wooster Group, Elevator Repair Service, Sasha Waltz, Heiner Goebbels, Sankai Juku etc. Muitos desses artistas são de esquerda, pessoalmente, mas na sua prática artística, em termos de espaços, audiências e efeitos no mundo político, essa esquerda é apolítica, um estilo de esquerda mais do que 
uma esquerda dos trabalhadores. Essa nichoguarda é o que faz a estase andar em círculos.

Por sessenta e cinco anos, desde o final da Segunda Guerra Mundial, a humanidade tem passado por sofrimentos extremos, mas não em geral. Não houve uma Terceira Guerra. Em vez disso, há sempre uma pequena guerra aqui, um genocídio acolá, uma catástrofe ecológica em algum outro lugar, um ataque terrorista, uma represália. Nós vivemos em uma atmosfera de perigo iminente antecipado por promessas de grandes avanços tecnológicos. Será que as calotas polares irão derreter, a diversidade de espécies diminuir de maneira drástica, os desertos se expandir, e assim por diante; e será que a engenharia genética, carros elétricos, moinhos de vento e painéis solares irão nos salvar... etc.? Mesmo que o seu poder esteja diminuindo, os Estados ainda são fortes o suficiente para provocar o caos. É impossível governar a internet - e isso é tanto glorioso quanto temível. Os terroristas operam fora do controle do Estado. Algumas regiões como o Afeganistão, o Iraque, Palestina-Israel e partes da África subsaariana sofrem há décadas sem ter um fim à vista. A mídia americana cria e exporta um tipo de entretenimento de informação ao emendar desastres causados pelo homem e desastres naturais: uma guerra, um tsunami, escassez, uma praga, um assassinato, uma crise econômica. Na mídia americana eventos reais são dramatizados e a ficção é apresentada como real. Tudo é arranjado em sequências que permitam o máximo de exploração comercial. Depois de genocídio, Mylanta; e, depois das notícias, Os Simpsons. Por causa da mídia - especialmente as telenotícias e a internet - os acontecimentos não mais parecem acontecer em tempos e lugares específicos. Uma imagem relembra ou repete uma série de outras - como se todos estivessem assistindo ao Hamlet do Wooster Group, onde a atenção muda de Scott Shepherd, com sua simulação meticulosa de Richard Burton para a imagem trêmula do vídeo de Richard Burton, que parece estar desaparecendo como o seu próprio fantasma enquanto nós o observamos. Para o Wooster, Shakespeare como tal não é importante, apenas a entrega, o efeito fantasmagórico de difícil definição. 
Cada vez mais artistas reagem à situação global e à sua própria atenuação ao refazer clássicos da vanguarda. A retrospectiva de Abramovic no MoMA atraiu um público recorde - para o quê? Para uma artista famosa sentada em exposição pública? Para ver performances autorais que eram ousadas demais quando realizadas pela primeira vez, mas que hoje são seguras por terem sido museificadas/mumificadas? Alguns meses depois, em setembro de 2010, o Whitney Museum refez várias peças de Trisha Brown dos anos sessenta aos setenta, incluindo Man Walking Down the Side of a Building. Exceto pelo fato de que não era um homem, mas a dançarina Elizabeth Streb quem caminhava ao longo da parede, que também não era o lado de um edifício de apartamentos, mas o exterior elegante do Whitney Museum. Eu estava no meio da multidão e senti certa emoção com a lembrança. Eu disse à editora associada do $T D R$, Mariellen Sandford, que estava ao meu lado, Isso é bom, isso é muito bom; não envelheceu. Eu estava errado, tinha envelhecido. Nós todos tínhamos. E nem mesmo o mais minucioso remake é capaz de ser a mesma coisa que a primeira vez. As circunstâncias mudam, o público é diferente, a memória em si tira da reperformance o choque do novo.

O que essas performances fazem é muito diferente daquilo que acontece na Metropolitan Opera ou em um dos teatros de grandes espetáculos da Europa quando uma nova interpretação de um clássico é apresentada. Os textos clássicos são supostamente reinterpretados, ganhando vida nova, tornados relevantes para o hoje. Uma certa excitação em tratar o antigo de uma forma nova causa deleite no público e, às vezes, perturba a crítica. De quantas novas maneiras os diretores podem renovar o ciclo do Anel de Richard Wagner? Depois do que fez com Tennessee Williams e Lillian Hellman, o que Ivo van Hove fará com... quem quer que seja? ${ }^{19}$

Mas, nas reperformances de trabalhos de vanguarda que estou discutindo - as apresentações de Abramovic ou Brown, as várias reinterpretações de sucessos experimentais do passado -, a ousadia da primeira performance necessariamente dá lugar à nostalgia da repetição. Essa nostalgia é tão reconfortante quanto deprimente. Quando um grande pedaço da 
vanguarda não mais vive no futuro, mas no passado, enquanto outro pedaço é uma marca e outro ainda é a nichoguarda, nós como pessoas - não apenas como artistas - sabemos que estamos vivendo em um tempo de oportunidades perdidas. No século XXI, mais do que no século XX, nós sabemos o que aflige o mundo, todavia, nossos líderes - e, indiretamente, nós mesmos - são incapazes de enfrentar ou mesmo resolver o que está errado. A vanguarda não responde com ataques ferozes aos corruptos, aos ineptos e aos maus, mas com repetições de si mesmas.

No entanto, essas reconstituições conservadoras, tão diferentes do que as vanguardas foram, estão possivelmente de acordo com a melhor e mais sábia instrução: reduzir, reciclar e reutilizar. Por que não deveria a arte também tornar-se ecológica e deixar uma pegada menor? É realmente ruim o fato de que as vanguardas sejam conservadoras? O melhor caminho para a frente, dadas as circunstâncias, não seria o de não se mover de forma alguma? Ou estaria eu interpretando mal o que está acontecendo? Rachel Chavkin, diretora do TEAM, vê o mundo de maneira diferente do modo como eu o vejo.

Os trabalhos que eu via quando era estudante eram muitas vezes miraculosos esteticamente e politicamente, mas também frequentemente impregnados de ironia. Eu não me refiro a uma ironia despropositada. Havia um sentimento profundo de que uma mudança não havia sido possível nos seres humanos. A política do país naquele momento refletia essa sensibilidade. [...] A minha geração é o produto de um novo movimento da juventude que eu acho - eu espero - que foi revigorado. Transformações políticas parecem ser novamente possíveis e o país parece acreditar nessa possibilidade de novo (Martin, 2010, p. 110).

Mostre-me. 


\section{Notas}

${ }^{1}$ Nome tirado do episódio final de Amerika, de Franz Kafka. Hoje em dia o Nature Theatre é muito Nova York e nada Oklahoma.

${ }^{2}$ Ironicamente, um ponto de vista originado pela retórica de muitos grupos novos de hoje.

${ }^{3}$ Para uma visão aprofundada desse novo trabalho, ver a edição especial de TDR 54, n. 4, 2010, editada por T. Nikki Cesare e Mariellen R. Sandford.

${ }^{4}$ Ver meu texto "9-11 As Avant-garde Art?" PMLA 124, n. 5, p. 1820-1829, 2009. Publicado em lingua portuguesa com o título "11 de Setembro, arte de vanguarda?", Revista Brasileira de Estudos da Presença, Porto Alegre, v. 1, n. 2, p. 404-425, jul./dez. 2011. Disponível em: $<$ http://seer.ufrgs.br/presenca/article/view/20986/14326>.

${ }^{5}$ Uma sigla em inglês para "science, technology, engineering, and mathematics". É claro que o "caule" (stem) é a continuação da raiz acima do solo: aquilo o que é essencial e formador. Significativamente, as artes não fazem parte do STEM.

${ }^{6}$ Um grupo de hackers que, durante a retaliação contra o WikiLeaks (a publicação na internet de memorandos classificados do Departamento de Estado dos EUA), teve sucesso em um ataque que tirou do ar temporariamente as páginas de internet das companhias Mastercard, Visa e Paypal, pois estas se recusaram a processar doações ao WikiLeaks. Uma verdadeira guerra cibernética.

${ }^{7}$ O comício de Beck, "Restoring Honor", foi parodiado por Colbert e Stewart no "Rally to Restore Sanity and/or Fear" [Comício para Restaurar a Sanidade e/ou o Medo]. O entretenimento está no coração de ambos - o banner com o título da página de Beck proclama "The Glenn Beck Program -the Fusion of Entertainment and Elightenment" [O Programa de Glenn Beck - a Fusão de Entretenimento e Iluminismo]. Disponível em: <http://www.glennbeck.com/ content/articles/article/198/44980/>.

${ }^{8}$ Há muitos relatos sobre a apresentação de Abramovic no MoMA. Eu recomendo o texto de Judith Thurman, "Walking Through Walls" The New Yorker, p. 24-30, March 8, 2010.

${ }^{9}$ Disponível em: $<$ http://www.elevator.org/shows/show.php?show=gatz $>$.

${ }^{10}$ Disponível em: <http://www.livingtheatre.org/history.html>. As datas de fundação dos outros são: Wooster Group, 1967 (como o The Performance Group, o nome de Wooster Group apareceu pela primeira vez em 1980); Richard Foreman/Ontological-Hysteric Theatre, 1968; Robert Wilson/Byrd Hoffman School of Byrds, 1969; Lee Breuer/Mabou Mines, 1970.

${ }^{11} \mathrm{O}$ Poor Theatre do Wooster consiste de simulações de uma demonstração em uma palestra do coreógrafo William Forsythe e das seções finais de Akropolis, do The Polish Laboratory Theatre, dirigido por Grotowski, com algumas breves seções originais sobre Max Ernst. Hamlet do Wooster projeta em uma grande tela seções do Hamlet de Burton, enquanto Scott Shepherd refaz Burton o mais precisamente o possível. Para boas análises dessas produções, ver David Savran, "The Death of the Avantgarde" TDR 49, n. 3, p. 10-42, 2005, e Kermit Dunkelberg, "Confrontation Simulation, Admiration: The Wooster Group's Poor Theatre" TDR 29, n. 3, p. 43-57, 2005. 
${ }^{12}$ Esse trabalho começou quando o que seria o Wooster Group, em 1980, ainda fazia parte do The Performance Group, o qual eu fundei e do qual eu fui o diretor artístico até 1980.

${ }^{13}$ Architecting (2008) do TEAM é relacionado, mas não idêntico em seu texto-como-texto em primeiro plano. Em Architecting, Margaret Mitchell - o seu Gone With the Wind à mão - é introduzida como consultora de uma versão filmada de seu romance, desta vez dirigida por um Afro-americano. Mitchell afirma que o novo filme - repleto de retórica politicamente correta sobre relações esclarecidas entre as raças - é tão falso em relação ao seu romance, e à história, quanto o filme de 1939 de David Selznick e Victor Fleming. Tudo isso no contexto de Nova Orleans pós-Katrina e à sombra de um homem silenciosamente construindo uma grande maquete da Catedral de Chartres: uma maquete de uma maquete da criatividade coletiva. Para discussões pormenorizadas do TEAM em geral e Architecting em particular, ver Carol Martin, "What Did They Do to my Country!: An Interview with Rachel Chavkin" TDR 54, n. 4, p. 108-117, 2010; Maurya Wickstrom, "The Labor of Architecting" TDR 54, n. 4, p. 118-135, 2010; Rachel Daniel, "Art in the Age of Political Correctness: Race in the TEAM's Architecting" TDR 54, n. 4, p. 136-154, 2010.

${ }^{14}$ Ver Allan Kaprow 1983, "The Real Experiment" in Essays on the Blurring of Life and Art, organizado por Jeff Kelley (Berkeley e Los Angeles: Univ. of California Press, 1983), p. 201-218.

${ }^{15}$ Em 2009, pelo Austin's Rude Mechanicals. Em sua produção, os Rudes tentaram duplicar o filme de 1969 de Brian DePalma sobre a produção do The Performance Group, em 1968. Ironicamente, uma performance que mudava a cada noite foi primeiro editada e congelada por DePalma e então recriada naquela forma pelos Rudes cuja produção ganhou o prêmio do Austin Critics Circle de teatro de 2009-2010.

${ }^{16}$ Ver meu texto Between Theater and Anthropology (Philadephia: Univ. of Pennsylvania Press, 1985), Performance Theory (New York: Routledge, 2003), e Joseph Roach, Cities of the Dead (New York: Columbia Univ. Press, 1996).

${ }^{17}$ Mencionando apenas alguns textos chave dos autores da época que eu estou discutindo: Sue-Ellen Case, Feminism and Theatre (New York: Routledge, 1988); Jill Dolan, The Feminist Spectator as Critic (Ann Arbor: Univ. of Michigan Press, 1991), Jill Dolan Presence and Desire (Ann Arbor: Univ. of Michigan Press, 1993); Judith Butler, Gender Trouble (New York: Routledge, 1990), Judith Butler, Bodies That Matter (New York: Routledge, 1993), Judith Butler, Excitable Speech (New York: Routledge, 1997); Peggy Phelan, Unmarked (New York: Routledge, 1993), Peggy Phelan, Mourning Sex (New York: Routledge, 1997).

${ }^{18}$ Ver Shannon Rose Riley e Lynette Hunter (Org.), Mapping Landscapes for Performance As Research (New York: Palgrave Macmillan, 2009).

${ }^{19}$ Conhecido por suas interpretações radicais, o diretor holandês van Hove montou A Streetcar Named Desire em 1999 e Little Foxes (2010) de Hellman no New York Theater Workshop de maneiras atípicas e geniais - colocando Blanche em uma banheira vaporosa no palco e retirando todos os móveis da casa dos Hubbard. 


\section{Referências}

BUTLER, Judith. Gender Trouble. New York: Routledge, 1990.

BUTLER, Judith. Bodies That Matter. New York: Routledge, 1993.

BUTLER, Judith. Excitable Speech. New York: Routledge, 1997.

CASE, Sue-Ellen. Feminism and Theatre. New York: Routledge, 1988.

CESARE, T. Nikki; SANDFORD, Mariellen R. (Org.). TDR, Cambridge, MA, MIT Press, v. 54, n. 4, inverno 2010.

DANIEL, Rachel. Art in the Age of Political Correctness: Race in the TEAM's Architecting. TDR, Cambridge, MA, MIT Press, v. 54, n. 4, p. 136-154, inverno 2010.

DOLAN, Jill. The Feminist Spectator as Critic. Ann Arbor: University of Michigan Press, 1991.

DOLAN, Jill. Presence and Desire. Ann Arbor: University of Michigan Press, 1993.

DUNKELBERG, Kermit. Confrontation Simulation, Admiration: The Wooster Group's Poor Theatre. TDR, Cambridge, MA, MIT Press, v. 29, n. 3, p. 43-57, outono 2005.

KAPROW, Allan. The Real Experiment. In: KELLEY, Jeff (Org.). Essays on the Blurring of Life and Art. Berkeley e Los Angeles: Univ. of California Press, 1983. P. 201-218.

MARTIN, Carol. What Did They Do to my Country!: An Interview with Rachel Chavkin. TDR, Cambridge, MA, MIT Press, v. 54, n. 4, p. 108-117, inverno 2010.

PHELAN, Peggy. Unmarked. New York: Routledge, 1993.

PHELAN, Peggy. Mourning Sex. New York: Routledge, 1997.

RILEY, Shannon Rose; HUNTER, Lynette (Org.). Mapping Landscapes for Performance As Research. New York: Palgrave Macmillan, 2009.

ROACH, Joseph. Cities of the Dead. New York: Columbia Univ. Press, 1996.

SAVRAN, David. The Death of the Avantgarde. TDR, Cambridge, MA, MIT Press, v. 49, n. 3, p. 10-42, outono 2005 .

SCHECHNER, Richard. Between Theater and Anthropology. Philadephia: Univ. of Pennsylvania Press, 1985.

SCHECHNER, Richard. Performance Theory. New York: Routledge, 2003.

SCHECHNER, Richard. 11 de Setembro, Arte de Vanguarda?. Revista Brasileira de Estudos da Presença, Porto Alegre, v. 1, n. 2, p. 404-425, jul./dez. 2011. Disponível em: <http://seer. ufrgs.br/presenca/article/view/20986/14326>. Acesso em: 01 nov. 2011.

THURMAN, Judith. Walking Through Walls. The New Yorker, New York, Condé Nast, p. 24-30, 8 mar. 2010.

WICKSTROM, Maurya. The Labor of Architecting. TDR, Cambridge, MA, MIT Press, v. 54, n. 4, p. 118-135, inverno 2010. 
Richard Schechner é doutor pela Tulane University. É fundador e professor do Departamento de Estudos da Performance da Universidade de Nova York. Autor de diversos livros e artigos, traduzidos em mais de quarenta línguas, incluindo Between Theather and Anthropology (Pensylvania University Press, 1985) e Performance Studies - an introduction (Routledge, 2006). Sua mais recente produção teatral foi Mandarin Hamlet (2009), encenado em Shanghai e Wroclaw.

E-mail: rs4@nyu.edu

Traduzido do original em inglês por Martin Dahlström Heuser e revisado por Marcelo de Andrade Pereira.

Recebido em 24 de junho de 2011 Aprovado em 31 de janeiro de 2012 